\title{
Ensino de Ciências e Recursos Tecnológicos nos Anos Iniciais da Educação Básica
}

\section{Science Teaching and Technology Resources in the Early Grades of Basic Education}

\author{
Verônica Gomes dos Santos \\ Brasil \\ Marcelo Zanotello ${ }^{\circledR}$ Brasil
}

Esta investigação empírica e qualitativa analisa práticas de ensino investigativas com o uso de recursos tecnológicos a fim de promover uma aprendizagem contextualizada em aulas de ciências nas séries iniciais da educação básica. Para tanto, foi elaborado um projeto que envolveu 56 alunos, com idades entre 6 e 7 anos, em uma escola pública paulista. O projeto teve início com o universo dos contos de fadas e desenvolveu-se através de atividades planejadas em uma perspectiva educacional construtivista. A análise das produções das crianças foi organizada em dimensões que permitem evidenciar, dentre outros aspectos: seu envolvimento e participação ativa, estimulados pelo uso dos recursos tecnológicos como um diferencial em relação às atividades convencionais instrucionais; indícios de uma formação conceitual em certos temas de física; uma capacidade em estabelecerem relações com situações cotidianas; e o desenvolvimento da autoria e do protagonismo na construção do conhecimento.

Palavras-chave: Educação Científica; Tecnologias; Ensino Fundamental I; Contos de Fada; Invenções.

This empirical and qualitative research evaluates investigative teaching practices that integrate technological resources, aiming at promoting contextualized learning in Science classes in the early years of basic education. To this end, we developed a project that involved 56 students, aged between 6 and 7 years, in a public school in the state of São Paulo. The project began with the fairytale universe and was developed through activities planned according to an educational perspective based on constructivism. The analysis of the pupils' output was organized in a way to reveal, among other aspects: their engagement and active participation, stimulated by the use of technological resources as a distinguishing feature in relation to conventional instructional activities; signs of a conceptual formation in certain subjects of physics; an ability to make connections with everyday situations, and the development of authorship and perception of the learners' role in building knowledge.

Keywords: Science Education; Technology; Early Years Education; Fairy Tales; Inventions. 


\section{Introdução}

O acesso crescente a diversos recursos tecnológicos influencia praticamente todos os setores de atuação humana, incluindo a escola. De acordo com Zandvliet (2012), a inserção cada vez mais acentuada das tecnologias da informação e comunicação (TIC) nos sistemas educacionais se deve a razões não somente de ordem pedagógica, mas também de ordens sociais, políticas e econômicas, refletindo-se pelo "aumento na quantidade de aparatos tecnológicos adquiridos para as escolas e pela diversidade de possibilidades de seus usos para fins didáticos, que têm sido objetos de debates e pesquisas" (Santos, Almeida, \& Zanotello, 2018, p. 332).

Apesar de certo consenso entre professores, estudantes, gestores de sistemas educacionais e determinados grupos de pesquisadores de que a inserção das TIC na educação pode colaborar, por exemplo, no desenvolvimento da capacidade dos estudantes em coletar informações, interagir com as fontes, analisar e interpretar dados, entender conceitos e princípios científicos, estimular a comunicação e a colaboração entre eles e com os professores através de originais e motivadoras atividades educativas, consideramos que estes potenciais benefícios devem ser investigados em situações práticas devidamente planejadas, pois não é apropriado supor que o mero emprego dos recursos tecnológicos vá, espontaneamente, transformar a educação (Osborne, \& Hennessy, 2003).

Para Buckingham (2010), é preciso que a inserção educacional das tecnologias seja pensada para além de simples formas de se combinar educação e entretenimento, bem como do enaltecimento dos potenciais educacionais atribuídos a elas. Nesse sentido, pesquisas podem fornecer subsídios para reflexões sobre práticas escolares envolvendo a integração de recursos tecnológicos diversos articulados aos currículos e de modo funcional para professores e alunos, a partir de uma definida e clara concepção pedagógica.

Em seu trabalho, Bingimlas (2009) identifica obstáculos frequentes para o sucesso de iniciativas que tentam integrar tecnologias ao ensino, tais como: sentimentos de falta de confiança e competência de certos professores no uso das tecnologias com fins didáticos; resistências a mudanças e atitudes negativas em algumas comunidades, por não estar claro como as tecnologias podem beneficiar as relações de ensino e aprendizagem; falta de tempo para a preparação de atividades explorando novos recursos tecnológicos e para desenvolvê-las em sala de aula; falta de treinamentos efetivos tanto de caráter pedagógico quanto tecnológico para o uso das TIC no ambiente escolar; acessibilidade precária à internet, hardwares e softwares apropriados; e a falta de suporte técnico e infraestrutura. Esses fatores fazem com que mesmo os professores que possuem bons projetos de integração de tecnologias em suas aulas os reduzem ou abandonem em determinadas situações.

Dentre os diversos obstáculos, focaremos nossa atenção naqueles que se referem diretamente a aspectos vinculados às práticas de ensino. Como menciona Cuban (2001), parcela considerável dos professores que empregam as TIC em suas aulas tende a usá- 
las para reforçar práticas de ensino instrucionais pouco efetivas e acabam por deixá-las à margem com o decorrer do tempo, evidenciando que a incorporação das tecnologias por parte dos professores não será automática. Referindo-se a Valente (1999), Zanotello et al. (2017) colocam que:

o computador e outros recursos tecnológicos, quando utilizados somente para transmitir informações, afirmando e dando continuidade a práticas essencialmente instrucionais, não provocam transformações, não alteram os processos de ensino e aprendizagem e não questionam as metodologias, fazendo com que a tecnologia não passe de mais um recurso substituível por qualquer outro com o propósito de "enfeitar" ou "dinamizar" a aula em nome de uma suposta inovação. Não será possível dimensionar o valor do uso das tecnologias para os processos de ensino e aprendizagem se não considerarmos o aluno como protagonista nestes processos e que seu conhecimento é construído a partir de relações estabelecidas por diversas formas de mediações (Zanotello et al., 2017, p.1136).

Em nosso entender, este ainda é um problema fundamental. A inserção das tecnologias com intencionalidade pedagógica definida e articulada aos currículos envolve necessariamente novas práticas e uma reconfiguração das relações de ensino e aprendizagem. O problema central deste trabalho pode, então, ser colocado do seguinte modo: em que aspectos o desenvolvimento de práticas que integrem recursos tecnológicos variados podem contribuir para a educação em ciências, a partir de práticas investigativas, de estudantes na faixa etária entre 6 e 7 anos que se encontram no início da educação básica?

Com base nesta questão, foram delineados os seguintes objetivos de pesquisa. De modo geral, pretendemos analisar contribuições e limitações de estratégias que utilizam certos recursos tecnológicos em aulas de ciências no ciclo I do ensino fundamental. Mais especificamente, visamos analisar como o trabalho com certos recursos tecnológicos pode auxiliar no desenvolvimento de uma atitude científica, investigativa, crítica e argumentativa dos alunos; comparar seus envolvimentos e interesses quando se empregam estratégias diversificadas e recursos tecnológicos variados para a promoção da educação científica, em relação aos observados em atividades instrucionais e explanatórias; e investigar se tais estratégias podem auxiliar os estudantes a compreender e relacionar os conceitos científicos abordados a situações cotidianas, contextualizandoos e atribuindo-lhes significados.

Na próxima seção apresentamos o referencial teórico em que nos baseamos com vistas à integração entre tecnologias e educação científica nos anos iniciais do ensino fundamental. Em seguida, detalhamos aspectos metodológicos relacionados à pesquisa que realizamos e ao desenvolvimento de um projeto didático desenvolvido com os alunos em uma escola pública. Na seção de análise apresentamos e discutimos as produções dos estudantes e concluímos o presente artigo com nossas considerações finais. 


\section{Perspectivas Construtivistas para a Educação Científica e o uso da Tecnologia}

Como referencial para pensarmos a educação científica e sua integração com recursos tecnológicos, nós consideramos o construtivismo e, mais especificamente, sua vertente sociocultural. Conforme Ogborn (1997), tal vertente aplicada à educação científica preserva ao menos quatro aspectos marcantes do construtivismo:

a importância do envolvimento ativo do aprendiz; o respeito pelo aprendiz e por suas próprias ideias; o entendimento da ciência enquanto criação humana; e a orientação para o ensino no sentido de capitalizar o que os estudantes já sabem e dirigir-se às suas dificuldades em compreender os conceitos científicos, em função de sua visão de mundo (Ogborn, 1997, p. 131).

A apropriação de perspectivas construtivistas pela educação científica foi intensa, em especial nas últimas décadas do século XX, influenciando desde estudos acadêmicos até diretrizes curriculares oficiais. Estes estudos preconizam que o ensino de ciências, já nos anos iniciais da educação básica, deve superar metodologias estritamente centradas no professor e na mera transmissão de conhecimentos, contemplando o ensino por investigação (Sasseron, 2015), a problematização (Silva, \& Penido, 2011), o levantamento de hipóteses (Nunes, \& Motokane, 2015), a experimentação, o estabelecimento de relações causais, a colaboração e a interação entre os pares, o desenvolvimento da criticidade e da capacidade de organização, bem como a análise de informações por meio de desenhos, tabelas, gráficos, esquemas e textos.

De acordo com Kerr e Murphy (2012), as atitudes das crianças em relação aos temas científicos e seus interesses nas aulas de ciências são importantes aspectos da educação científica escolar a serem considerados. Segundo as autoras, é fundamental propiciar oportunidades às crianças se expressarem sobre ciências de maneiras variadas e pelas quais se sentirem mais confortáveis. Escrevendo, falando, desenhando ou construindo protótipos, elas podem expor seus pontos de vista sobre o problema proposto, estimuladas por mediações conduzidas pelo professor e que envolvam questões de natureza aberta.

Murphy e Beggs (2003) sondaram o que as crianças gostavam e não gostavam de fazer nas aulas de ciências, evidenciando a preferência delas por experimentos e práticas investigativas que permitem participação ativa e expressão de ideias. Estes aspectos têm implicações metodológicas para pesquisas que propõem analisar o envolvimento das crianças em aulas de ciências, com Blalock et al (2008) destacando a importância de se empregar instrumentos diversos para analisar as atitudes e produções dos alunos em relação às ciências.

Conforme Murphy (2012), a aprendizagem das ciências está relacionada aos contextos sociais e culturais específicos nos quais os aprendizes estão envolvidos, preconizando que a aprendizagem ocorre inicialmente pela interação entre os pares e, então, processando-se em nível individual, com os conceitos científicos sendo 
formados gradualmente pela combinação de experiências e operações mentais baseadas em variadas formas de linguagem. Em uma abordagem sociocultural para as ciências nas séries iniciais, é necessário que as atividades práticas estejam vinculadas a um referencial conceitual, que as crianças sejam estimuladas a discutirem as atividades e suas compreensões entre si e com o professor, com tempo hábil para as discussões e a sistematização conceitual a partir das atividades desenvolvidas.

O professor é essencial para orientar o trabalho e mediar com os alunos os referenciais conceituais significativos para as tarefas que estão realizando. Murphy (2012) afirma que a efetividade das atividades será maior se as crianças usarem modelos simbólicos e esquemáticos para representarem os problemas e os procedimentos que estão empregando para resolvê-los. O uso desses modelos, com as reflexões que explicitam as formas de pensar e as questões dos estudantes podem tornar a aprendizagem significativa, fazendo com que eles desenvolvam gradativamente compreensões cada vez mais próximas da visão conceitual científica e apliquem o conhecimento em situações de seu cotidiano.

Referindo-se à utilização didática de recursos tecnológicos na educação científica, Webb (2005) destaca que:

As potencialidades identificadas apoiam a aprendizagem através de quatro efeitos principais: promover a aceleração cognitiva; permitir uma ampla gama de experiências para que os alunos possam relacionar a ciência com suas próprias experiências e com outras experiências do mundo real; aumentar a autogestão dos alunos; e facilitar a coleta e apresentação de dados (Webb, 2005, p. 705 - tradução nossa).

Costa et al. (2012) afirmam que, ao considerar o uso das TIC em uma perspectiva construtivista, trata-se de repensar as aprendizagens previstas nos currículos "com base no que as TIC permitem hoje fazer e que não poderia ser feito antes delas existirem" (Costa et al., 2012, p. 26), ressaltando que:

A mudança de paradigma sobre o que é ensinar e aprender, em direção a uma lógica sócio construtivista, parece-nos ser, aliás, o contexto ideal para se tirar partido do que designamos por potencial transformador das TIC. Aqui, as tecnologias digitais são uma ferramenta cognitiva do aluno, porque o ajudam, sobretudo, a pensar e resolver problemas, a criar e a expressar-se, a interagir e colaborar com os outros. (Costa et al., 2012, p. 31).

Ainda com base em Costa et al. (2012), Santos, Almeida e Zanotello (2018) argumentam que as tecnologias podem ser usadas para auxiliar na promoção de objetivos educacionais orientados por uma perspectiva socioconstrutivista, tais como:

[...] desenvolver no aluno a capacidade de analisar, avaliar e decidir sobre os problemas que lhe são propostos; utilizar as tecnologias digitais para buscar informações, selecionando-as em função de critérios previamente estabelecidos; refletir sobre o que aprende e como aprende exercitando sua autonomia intelectual; comunicar-se, interagir e colaborar com os colegas; expressar-se, imaginar e criar empregando as diferentes formas de representações e combinações viabilizadas pelas tecnologias digitais (Santos, 
Almeida, \& Zanotello, 2018).

Souza e Fazenda (2017) exemplificam práticas com o uso de variadas mídias e estratégias para sistematizar conceitos a partir de criações autorais dos estudantes. Allison e Goldston (2018) investigam a convergência entre "multiletramentos" e práticas científicas mediadas por recursos tecnológicos em uma turma de quinto ano. O termo "multi" em "multiletramento" diz respeito à multiplicidade de letramentos em termos de multimodalidade e diversidade linguística e cultural. Ao se tornarem cientificamente letrados, os alunos devem ser capazes de atribuir sentidos a partir de uma variedade de recursos multimodais, como linguísticos, audiovisuais, gestuais e espaciais, e então utilizar os novos conhecimentos para explicar e prever fenômenos. Esta capacidade de utilizar os conhecimentos constituídos na educação escolar em situações diversas parece-nos ser uma evidência da ocorrência de uma aprendizagem significativa.

Baseando-nos nessa perspectiva para o ensino de ciências mediado por recursos tecnológicos privilegiando práticas investigativas, delineamos um projeto em parceria com as professoras de uma escola pública paulista, detalhado na seção seguinte onde tratamos de aspectos metodológicos relacionados à nossa investigação.

\section{Aspectos metodológicos}

Esta pesquisa qualitativa e empírica (Bogdan, \& Biklen, 1994) foi realizada em uma escola pública municipal da cidade de São Bernardo do Campo, no Estado de São Paulo. A escola conta, em sua infraestrutura, com um laboratório de informática e alguns netbooks para uso de professores e alunos.

As atividades propostas aos estudantes foram planejadas e realizadas em conjunto entre pesquisadores e as professoras das turmas envolvidas. Na ocasião, uma das pesquisadoras exercia a função de $\mathrm{PAPE}^{1}$, sendo responsável por acompanhar e auxiliar professores e alunos em atividades no laboratório de informática e que envolvam o uso das TIC na escola. A existência da função de PAPE nesta rede municipal de ensino revela uma preocupação em cuidar para que os professores sintam-se amparados e tenham apoio técnico adequado para utilizarem recursos tecnológicos, contribuindo para contornar alguns dos obstáculos apontados por Bingimlas (2009). Trata-se de uma pesquisa ação (Thiollent, 2011).

As turmas participantes foram escolhidas em função da disposição mostrada por suas professoras para desenvolverem as atividades no âmbito da pesquisa proposta. As duas turmas envolvidas pertenciam ao $2^{\circ}$ ano, uma no período matutino e outra no período vespertino, cada uma delas com 28 alunos com idades entre 6 e 7 anos, totalizando 56 alunos.

1 PAPE (Professor de Apoio aos Programas Educacionais): Esta função é ocupada por professores da rede de São Bernardo do Campo em função gratificada e que atuam dentro dos laboratórios de Informática de cada escola, estabelecendo uma relação direta no planejamento, acompanhamento e desenvolvimento de atividades, sequenciadas e projetos com o uso das mídias em geral (Laboratório e Laptops). 
A seleção dos instrumentos de coleta de dados levou em consideração a diversidade de possibilidades para este tipo de pesquisa, tendo sido registradas e analisadas: produções escritas e ilustrações, registros de fotografia e filmagem, diário de observação dos pesquisadores e um questionário semiestruturado. $\mathrm{O}$ questionário semiestruturado foi aplicado ao final do projeto, com perguntas de natureza aberta, respondidas por escrito pelas crianças. Durante a aplicação do questionário os estudantes estiveram organizados em assentos individuais e as questões foram lidas pelas professoras para as turmas.

Para Ariza e Armenteros (2014), a intencionalidade pedagógica e não o simples emprego de aparatos tecnológicos é que poderá auxiliar de fato na aprendizagem dos estudantes. Portanto, é de fundamental importância planejar adequadamente experiências colaborativas de uso das TIC em sala de aula. Um design que seja capaz de propiciar mediação do recurso tecnológico por e com o professor é necessário para viabilizar a aprendizagem de habilidades específicas para todos os alunos. De acordo com McNaughton et al. (2018), tanto a eficácia quanto a consistência dos efeitos do uso das TIC dependem do planejamento e do gerenciamento deliberados das ferramentas e de suas funções. As atividades desenvolvidas que constituem a parte prática da pesquisa foram organizadas na forma de um projeto didático elaborado em colaboração entre professoras e pesquisadores, descrito a seguir.

\section{O projeto "Os Contos de Fadas e as Invenções Tecnológicas"}

O projeto foi planejado a fim de apresentar as seguintes características:

- Organização em grupo do trabalho, proporcionando interações entre alunos, professoras e PAPE, promovendo a aprendizagem a partir do diálogo e da construção coletiva de ideias.

- Utilização de variados recursos procurando contemplar diferentes estilos de aprendizagens e promover relações com os conteúdos de forma integrada ao currículo e contextualizada.

- Problematização constante e motivadora, buscando desenvolver a capacidade investigativa e o interesse pelos conteúdos científicos de modo significativo.

- Produção autoral, tanto coletiva quanto individual, durante todo o desenvolvimento do projeto, culminando na elaboração de um produto real e socialmente funcional.

Na ocasião, a unidade escolar parceira da presente pesquisa planejou, para o decorrer do ano letivo, o trabalho em ciências com as séries inicias do nível I do ensino fundamental com base na temática "tecnologia, energia, transformações físicas e químicas da matéria”. A partir de uma abordagem inicial de conceitos como peso, massa, força e o estudo de máquinas simples como polias, roldanas, engrenagens e alavancas, 
que fosse adequada à faixa etária dos estudantes, foi elaborado o projeto "Os Contos de Fadas e as Invenções Tecnológicas”. A opção por se trabalhar com contos de fada se deve ao fato de se tratar de um gênero textual conhecido pela maioria das crianças, com potencial para criação de um enredo necessário para o estabelecimento de relações entre o fantástico e o real.

A estrutura do projeto é composta por 7 eixos temáticos para serem trabalhados ao longo do ano letivo. Cada eixo contém: um conto de fadas; uma invenção tecnológica condizente com um problema construído a partir do conto; a identificação de um mecanismo responsável pelo funcionamento da invenção tecnológica abordada; um conceito físico relacionado ao mecanismo abordado; uma montagem com material estruturado; e momentos de pesquisa na internet, de tratamento das informações e de ilustração tecnológica ou real.

A Figura 1 mostra os contos de fadas, as invenções tecnológicas e os mecanismos constituintes de cada eixo.

\begin{tabular}{|c|l|l|l|}
\hline Eixo & Conto de Fadas & Invenção Tecnológica & Mecanismo \\
\hline 1 & João e o pé de feijão & Elevador & Manivela \\
\hline 2 & A princesa e o grão de ervilha & Guindaste & Polias e Roldanas \\
\hline 3 & Branca de Neve e os sete anões & Batedeira & Engrenagens \\
\hline 4 & Cinderela & Carros & Rodas e Eixos \\
\hline 5 & A pequena Sereia & Caravela & Estrutura \\
\hline 6 & Rapunzel & Escorregador & Plano Inclinado \\
\hline 7 & A Bela Adormecida & Catapulta & Alavanca \\
\hline
\end{tabular}

Figura 1. Os eixos do projeto com os respectivos contos, invenções e mecanismos

Os conceitos físicos trabalhados em uma abordagem inicial para que as crianças tentem compreender o funcionamento dos mecanismos foram os seguintes: movimento e repouso, direção e sentido, movimentos retilíneos e circulares, forças e equilíbrio, energia. O desenvolvimento de cada eixo consistiu das seguintes etapas:

- Apreciação dos contos escolhidos: leitura do conto para as crianças, ou exibição através de filme. $\mathrm{O}$ uso de mídias, portadores e gêneros textuais variados, com linguagens e formatos diversos, pode propiciar uma aprendizagem integral, além da inclusão de alunos com dificuldades de aprendizagem e com necessidades educacionais especiais.

- Levantamento da problemática central: para introduzir a invenção tecnológica anacrônica ao período do conto, foi preciso dar ênfase a uma situação-problema gerada a partir do conto e estimular o levantamento de ideias e sugestões por parte das crianças. Por exemplo, soluções para ajudar o João a subir com a família para o castelo depois da morte do gigante, ou como ajudar a princesa a subir na torre tão alta, ou ainda, o que poderia auxiliar Branca de Neve a fazer tantas panquecas para o café da manhã dos anões, foram algumas perguntas colocadas para estimular uma reflexão coletiva. 
- Levantamento de hipóteses: falar, ouvir, respeitar sua vez, considerar a ideia do colega, refletir sobre as hipóteses, analisar, reconsiderar e escolher foram aspectos trabalhados em um momento de conversa coletiva. De posse da situação problema, os alunos apresentaram ideias de possíveis soluções que eram anotadas e, posteriormente, questionadas sobre sua pertinência ou funcionalidade para resolver a situação.

- Montagem com material estruturado: uma forma de concretização da invenção selecionada, de promoção do lúdico e do raciocínio, é a utilização de material estruturado. Nesse caso, foi usada a caixa 9674 da Lego Dacta $(\text { Edacom })^{2}$, disponível na escola. A proposta inicial era a montagem, em grupos, da invenção para, em seguida, problematizá-la, colocando em jogo o conhecimento adquirido, as capacidades de argumentação e do teste experimental.

- Pesquisar, aprofundar, conhecer: a etapa de pesquisa na internet teve a intenção de fazer com que os alunos percebessem que toda invenção tecnológica é uma produção humana, que passa por transformações ao longo da história e que existe um modo de funcionamento através de um mecanismo, que seria destacado posteriormente. Estes momentos propiciavam o exercício investigativo, o levantamento, a sistematização e tratamento das informações.

- Retomada da pesquisa, descoberta do mecanismo: a retomada coletiva da pesquisa era realizada para promover o tratamento das informações, confrontando fontes variadas e eventuais informações divergentes encontradas pela turma. Este momento também foi utilizado para se chegar ao mecanismo que é responsável pelo funcionamento da invenção tecnológica estudada.

- Compreensão de conceitos: o trabalho com alguns conceitos científicos da física surgiram ao se abordar os mecanismos. $\mathrm{O}$ "como funciona" era o gerador do tema e, através de questões que induzem a participação por levantamento de hipóteses, os alunos atribuíram determinados sentidos para os conceitos. Perguntas como "Se eu virar a manivela para a direita o que acontece? E se for para a esquerda?” ajudavam na produção de significados.

- Ilustração tecnológica ou real: quanto maior o estímulo aos alunos através de atividades concretas ou ilustradas com objetos de aprendizagens, maior é a resposta positiva, coerente e significativa que se espera que eles produzam. Assim, agregou-se ao trabalho momentos onde a turma assistia uma animação, brincava em jogos virtuais, ou passava por situações reais que promoviam a reflexão sobre os conceitos, possibilitando construir gradualmente uma conceituação teórica a partir dos momentos vivenciados na prática, no lúdico e no virtual.

2 Criada pela empresa LEGO, as caixas da Lego Dacta, como kits educacionais, visavam o trabalho ao longo da educação básica, desde a educação tecnológica até a robótica programável. A caixa 9674 é a segunda do kit, que permite o trabalho com máquinas simples, abordando conceitos como os propostos na pesquisa. Outras informações: http://lego.brickinstructions.com/en/lego_instructions/set/9654/Early_Simple_Machines_II_Set 
Ao final do projeto, os alunos produziram coletivamente um álbum de figurinhas contendo textos e ilustrações sobre as personagens dos contos, os recursos tecnológicos, os mecanismos e conceitos da física. Este produto final foi adequado à faixa etária da turma, dando sentido à função social da escrita, colocando à prova os conteúdos abordados durante o projeto revisitando-os de forma significativa e estimulando a autoria.

Todo o registro fotográfico, produções, filmagens e materiais utilizados como suporte, além do relato de cada etapa dos sete eixos temáticos, podem ser encontrados no endereço http://labneusamacellaro.wix.com/tecnologiasnoscontos hospedado, conforme orientação da Secretaria Municipal de Educação de São Bernardo do Campo, no blog institucional da escola.

Entretanto, questões de ordem prática surgem. Não houve tempo suficiente no cronograma escolar para que todos os conteúdos previstos para o ano letivo fossem desenvolvidos conforme o planejamento nos eixos, com atividades tecnológicas. Estas demandam mais tempo que as atividades convencionais que utilizam como únicos recursos os textos informativos do livro didático e, como estratégias, cópias de resumos colocados na lousa, exposição oral para explicação dos conceitos e questionários com perguntas fechadas como avaliação. Em vista dessa limitação, surgiu a possibilidade de sondarmos qualitativamente o engajamento das crianças nas aulas de ciências quando desenvolvidas de modos diferentes: com as atividades propostas nos eixos e com atividades convencionais de caráter instrucional.

As duas turmas participantes do projeto tiveram ambos os tipos de atividades em períodos distintos, alternadamente. Dessa forma, procuramos não fazer distinção entre as turmas ao garantir que ambas tivessem as mesmas oportunidades de aprendizado e desenvolvimento, ainda que não simultaneamente, oferecendo condições similares aos estudantes para produção de sentidos. O projeto de pesquisa foi aprovado e os instrumentos de coleta de dados foram autorizados tanto pelo Comitê de Ética da Universidade como pela Direção da unidade escolar participante, com os termos de consentimento livre e esclarecido assinados pelos responsáveis pelas crianças e pela direção da escola.

\section{Resultados e Análises}

Durante o desenvolvimento do projeto ao longo de um ano letivo, diversas produções e situações significativas foram registradas. A apresentação seguinte está organizada a partir de certas dimensões/categorias definidas com base nos métodos da análise de conteúdo (Bardin, 2011) e sistematizadas em função dos objetivos da pesquisa. Na utilização desse método de análise, todo material coletado foi explorado e lido preliminarmente, selecionando-se e registrando-se as partes mais significativas na forma de episódios, nos quais se evidenciam elementos que nos permitem responder aos objetivos da investigação. Tal procedimento nos permitiu a elaboração das dimensões apresentadas e discutidas em seguida. Nas transcrições de trechos das produções das 
crianças mantemos a forma original de suas grafias e falas, preservando suas identidades.

\section{Posicionamentos e preferências dos alunos}

A Figura 2 mostra como os conteúdos programáticos dos eixos 4 e 5 foram trabalhados com as duas turmas, designadas por A e B. "Atividades convencionais" refere-se a aulas instrucionais e "atividades tecnológicas" refere-se ao desenvolvimento do eixo conforme o projeto. Nas atividades convencionais, as professoras leram os contos com as crianças, problematizando a invenção tecnológica e o mecanismo envolvido em seu funcionamento em rodas de conversa. Mas, em seguida passavam às atividades convencionais de leitura do livro didático, resumos na lousa, exposição oral dos conceitos e questionários com perguntas fechadas.

\begin{tabular}{|l|l|l|}
\hline & Eixo 4 - Cinderela & Eixo 5 - A pequena sereia \\
\hline Turma A & Atividades convencionais & Atividades tecnológicas \\
\hline Turma B & Atividades tecnológicas & Atividades convencionais \\
\hline
\end{tabular}

Figura 2. Esquema de trabalho dos conteúdos programáticos dos eixos 4 e 5 em cada turma

A primeira pergunta aos alunos no questionário, que permitiu sondar suas impressões acerca do trabalho realizado, foi:

\section{Questão 1: Com qual conto você gostou mais de trabalhar?}

Conforme a Figura 3, a maioria dos estudantes em ambas as turmas indicaram como preferido o conto que foi trabalhado de forma diversificada com os recursos tecnológicos, indicando o quanto as estratégias de ensino parecem ser importantes no envolvimento das crianças. A motivação e o engajamento das crianças foram mais evidentes na realização das "atividades tecnológicas".

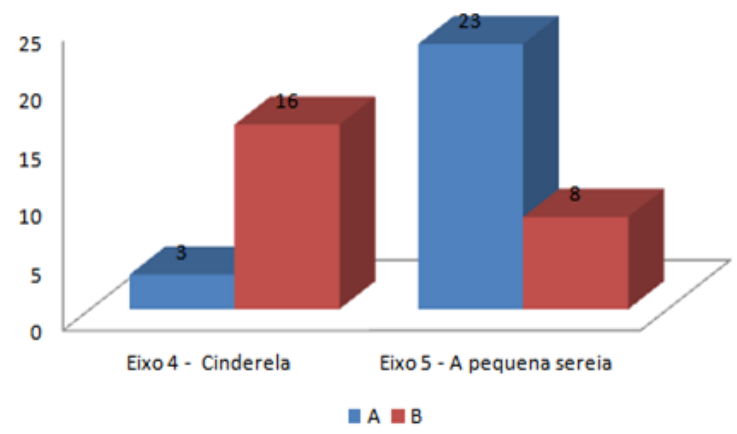

Figura 3. Preferências pelo conto nas turmas $\mathrm{A}$ e $\mathrm{B}$, a partir das respostas à primeira questão

Entretanto, esperava-se que algumas respostas seriam determinadas apenas pela preferência pessoal da fantasia que o conto pode despertar. Como exemplo dessa situação, algumas crianças da turma $\mathrm{B}$ que escolheram o conto trabalhado convencionalmente apresentaram justificativas como: 
"Por que ela vira humana por 3 dias..." - aluna $\mathrm{P}$

“O conto que eu mais gostei foi a pequena sereia, ela é muito linda." - aluna $\mathrm{S}$

Isso indica que a primeira questão poderia ter sido formulada de outra maneira. A segunda questão pretendia verificar o que cada estudante se lembrava de ter realizado durante o trabalho com o conto escolhido como preferido.

\section{Questão 2: Escreva o que você lembra que fizemos durante o trabalho com este conto.}

As Figuras 4 e 5 ilustram alguns tipos de respostas dadas pelos alunos à questão 2, procurando destacar a variedade de suas colocações. A partir destes relatos foi possível identificar quais recursos, naquele momento, pareciam ter melhor atraído o interesse dos alunos, por terem sido citados nas respostas à questão 2. A Figura 6 sintetiza esse resultado.

\begin{tabular}{|l|l|}
\hline Cinderela & A pequena Sereia \\
\hline $\begin{array}{l}\text { Eu lembro que aprendi sobre rodas e } \\
\text { aprendi sobre carros. } \\
\text { Carro desenhado - atividade de pesquisa. } \\
\text { Eu pesquisei a batedeira. }\end{array}$ & $\begin{array}{l}\text { Nós fizemos um teste com um barco na água para o } \\
\text { caso da pequena sereia. } \\
\text { Eu lembro que eu fiz um barco, colocou na água } \\
\text { e não ficou navegando. A gente foi construindo e } \\
\text { construindo e conseguimos fazer ele navegar. } \\
\text { Construir uma caravela com o lego e fizemos desenhos } \\
\text { e pesquisamos. }\end{array}$ \\
\hline
\end{tabular}

Figura 4. Algumas respostas da turma A à questão 2

\begin{tabular}{|c|c|}
\hline Cinderela & A pequena Sereia \\
\hline $\begin{array}{l}\text { Eu lembro que fomos para o laboratório de } \\
\text { Informática, assistimos o filme, montamos um } \\
\text { carro de lego e um grupo falou sobre o eixo. }\end{array}$ & $\begin{array}{l}\text { A Verônica contou uma história para a gente. } \\
\text { A gente ouviu a história, comentou sobre a } \\
\text { história e a Verônica fez perguntas. }\end{array}$ \\
\hline $\begin{array}{l}\text { Nós fizemos o carro para transportar a cinderela de } \\
\text { peça de montar. Assistimos o filme da Cinderela. }\end{array}$ & $\begin{array}{l}\text { Eu lembro que na sala nós lemos... } \\
\text { (reproduziu parte do conto). }\end{array}$ \\
\hline $\begin{array}{l}\text { Eu lembro que a gente viu o filme no laboratório, } \\
\text { que montamos o carro da Cinderela, nós também } \\
\text { vimos os tipos de carros e de carruagens. }\end{array}$ & $\begin{array}{l}\text { Eu ouvia a história - A Verônica comentou } \\
\text { que a pequena sereia fica no mar. }\end{array}$ \\
\hline
\end{tabular}

Figura 5. Algumas respostas da turma B à questão 2 


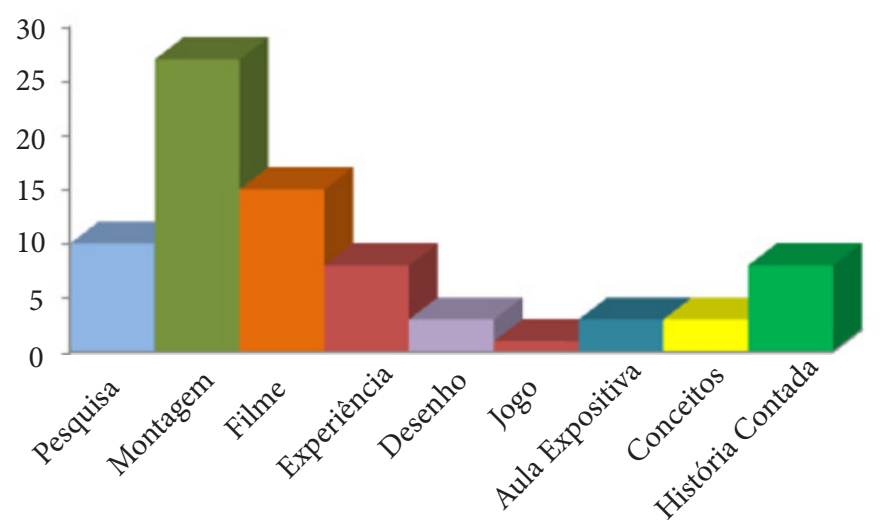

Figura 6. Frequência da citação de recursos nas respostas à questão 2

Os resultados evidenciam o valor do caráter lúdico da etapa de montagem do protótipo e suas potencialidades quando trabalhado com a devida intencionalidade pedagógica e problematizado constantemente, como na fase da montagem com o Lego. Esta fase propiciou um ambiente prazeroso e agradável no qual se observaram interações entre os pares em um processo de aprendizagem colaborativa, promovendo condições para a construção do conhecimento. Durante o ato de brincar, a colocação de desafios, a socialização e as interações estabelecidas contribuíram para o desenvolvimento mútuo dos envolvidos. A importância do brincar na formação das crianças é reconhecida, porém seu espaço dentro da escola ainda parece ser pouco explorado.

\section{Formação conceitual}

A terceira questão procurou investigar o que as crianças consideraram ter aprendido no trabalho com o conto que indicaram como preferido.

\section{Questão 3: O que você aprendeu com este conto que escolheu?}

Nesta faixa etária, os estudantes podem fornecer respostas incompletas ou curtas devido a dificuldades em se expressarem por escrito. Mas, mesmo assim, é possível revelarem indícios do que foi mais significativo para eles em termos de novas aprendizagens.

As respostas dadas à questão 3 foram classificadas em categorias definidas em função dos aspectos que eram mencionados: história da invenção do aparato tecnológico, mecanismo, conceito, contos de fadas ou outras curiosidades que faziam referência ao trabalho. 


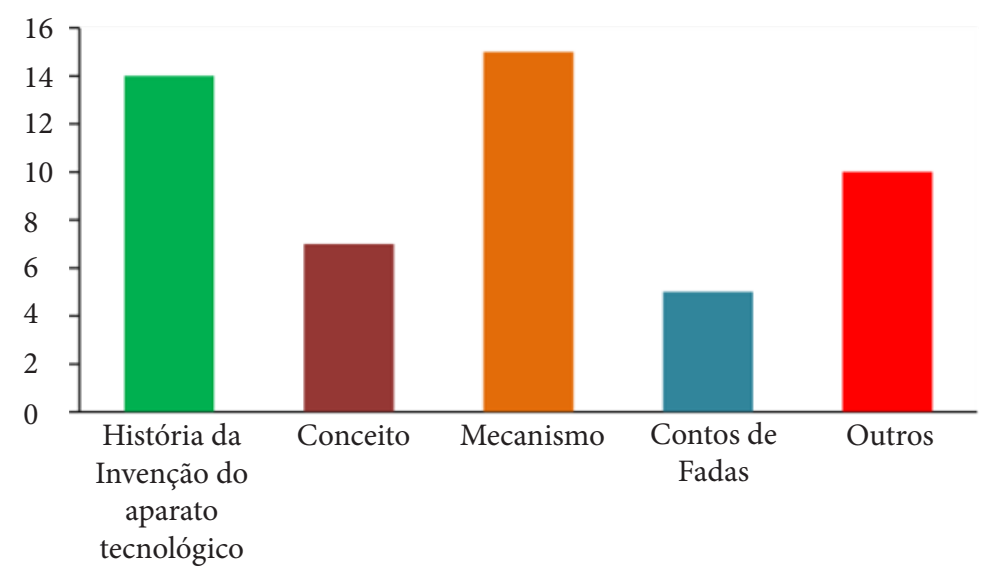

Figura 7. Respostas à questão 3 nas categorias definidas

As transcrições de algumas respostas exemplificam o que os alunos consideraram como aprendizado com o desenvolvimento do eixo em questão:

Eu aprendi que a caravela foi feita de madeira - aluna $\mathrm{M}$.

Que a caravela funciona com a força do vento - aluna C.

Eu aprendi que os carros tinham pauzinhos que se chamam eixos e que sem eles o carro não anda e que ele prende o volante e as rodas para elas se moverem para onde o volante está se movendo - aluna L.

Eu aprendi como a caravela boiava e ficava em cima da água boiando - aluna $\mathrm{M}$

Eu aprendi o que era uma caravela e que ela tem que ter equilíbrio - aluno R

Eu aprendi sobre o eixo e que sem o eixo as rodas do carro não funcionam - aluna $\mathrm{G}$

Embora os questionários viabilizem elementos para uma reflexão acerca da questão central desta pesquisa, este instrumento, por si só, limita os registros da produção das crianças, não dando oportunidade de expressão adequada àqueles alunos para os quais as dificuldades relacionadas à capacidade de expressão pela linguagem escrita não os impediram de participar ativamente do processo. Assim, recorreu-se também ao uso de ilustrações e desenhos livres como exemplificado na Figura 8.

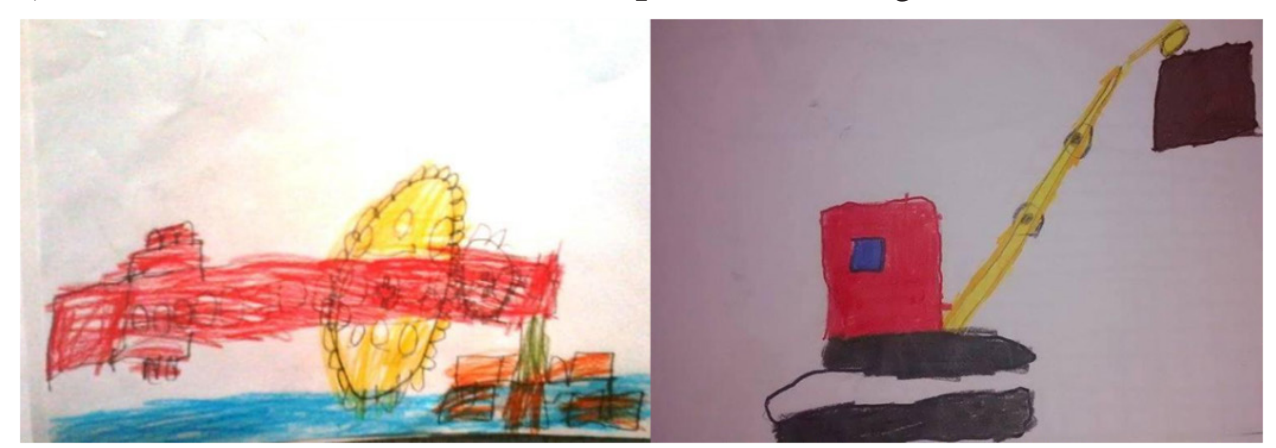

Figura 8. Exemplos de desenhos produzidos pelos estudantes 
Os desenhos são essencialmente sistematizadores, formas de retomada das aulas anteriores, onde se apresentam alguns mecanismos trabalhados com as turmas. Por exemplo, na figura 8 representam-se as engrenagens correspondentes ao eixo 3, bem como as polias e as forças associadas ao eixo 2.

Durante uma roda de conversa registrada após a aplicação do questionário, ao ser perguntado pela pesquisadora o que eles lembravam sobre os mecanismos que haviam estudado, mediações dialogadas como a exemplificada no episódio 1 mostram uma interessante discussão conceitual.

\section{Episódio 1:}

Agora a última pergunta para encerrar. Quero ver se está tudo fresquinho na cabeça de vocês. Vou escolher uma pessoa para me contar, ok? A, você se lembra para que serve uma engrenagem? - pesquisadora.

Pra funcionar, daí ela vai girar e vai fazer a força em todas - aluno A.

Isto mesmo. E cadê o P? Ah, está ali. P, você lembra como a gente usa uma manivela? pesquisadora.

Você vai girar para funcionar para um lado e gira depois e funciona do outro. Assim, sobe e desce - aluno P.

Quem se lembra.... vamos ver, a MF, pode ser? Você se lembra para que a gente usa uma polia? Roldana e polia? - pesquisadora.

Manifestações da turma não deixaram a aluna responder, tendo destaque uma resposta do aluno R.

É para levantar as coisas pesadas que a gente não consegue levantar. A gente põe uma corda e uma polia e puxa - aluno R.

E aí a gente faz mais ou menos força com mais polias? - pesquisadora.

Menos, bem menos força - aluno R.

A polia diminui a força - aluna C.

A sistematização final para a produção do álbum de figurinhas, ilustrada na Figura 8, se tornou um modo de revisar conceitos. O diálogo e a interação durante a produção do álbum permitiu retomar e registrar aspectos de conteúdos trabalhados há meses e que faziam sentido para eles. 


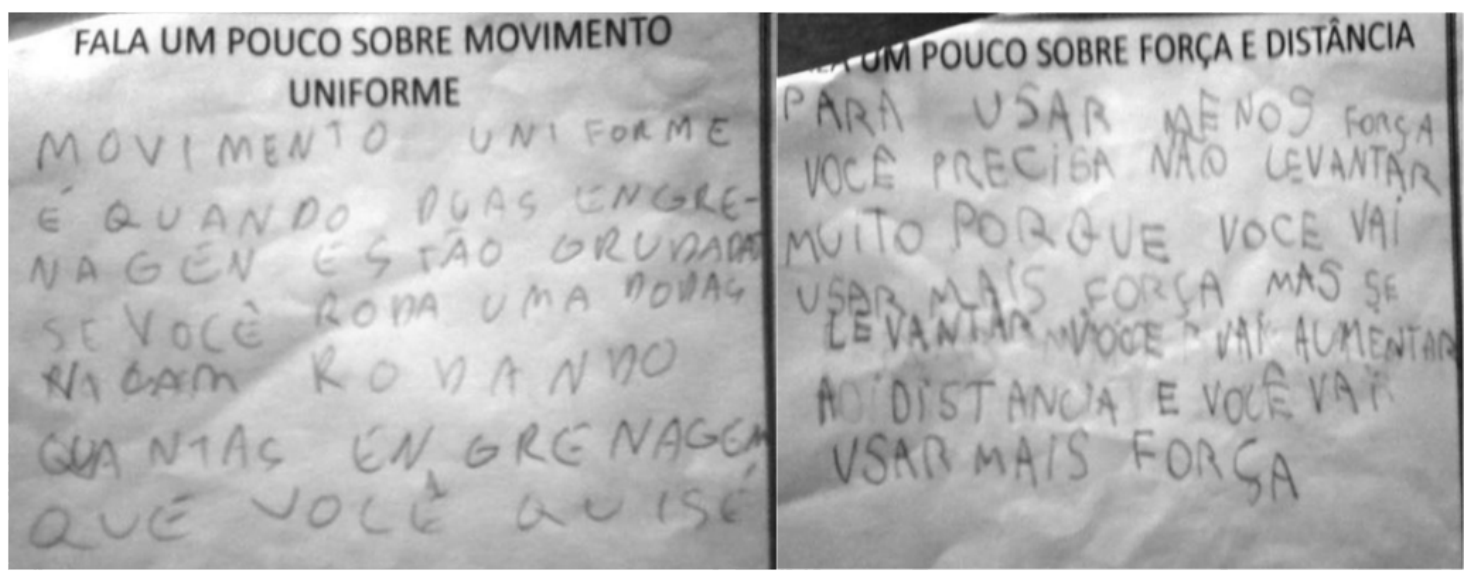

Figura 8. Exemplos de sistematização de conceitos para produção do álbum³

\section{Formação colaborativa e crítico-investigativa}

A participação dos alunos ao expressarem-se oralmente compartilhando ideias e posicionando-se criticamente acerca de informações adquiridas durante as etapas de pesquisa, montagens e tratamento das informações, foi registrada por meio de fotografias, filmagens e anotações no diário de observação. Muitas destas situações evidenciam a capacidade dos alunos em estabelecer uma relação dialógica de interação entre os pares e posicionarem-se pessoalmente a partir de reflexões e tomadas de decisão.

A Figura 9 apresenta situações nas quais cada grupo, para atender à solicitação da professora, precisava colocar em jogo a capacidade de negociar, expressar ideias, abrir mão, fazer escolhas e trabalhar em conjunto. Nesta atividade específica, os alunos receberam uma montagem inicial e a orientação para que a completassem de forma que, ao se rodar a manivela de um lado, as pás do outro lado começassem a girar. Para resolver o problema com os materiais disponíveis, os estudantes precisaram montar uma combinação de engrenagens de tamanhos diferentes presas por eixos em um suporte.

Um trabalho como este, que propicia a interação, o diálogo e a negociação, pode promover uma relação com o outro, pautada no respeito e na colaboração. Cenas como as registradas na Figura 9 foram observadas diversas vezes durante o projeto, permitindo às professoras e pesquisadores notarem uma qualidade crescente nas interações entre as crianças, nas suas capacidades investigativas e na aprendizagem colaborativa. Tais situações possibilitam às crianças organizarem seus pensamentos, estabelecendo relações que lhes permitam coordenar diferentes pontos de vista e integrá-los de maneira lógica e coerente, alcançando funções superiores consolidadas com a internalização (Oliveira, 2006). O exercício dessas habilidades mentais pela interação entre os pares é viabilizado a partir de objetos concretos e a proposição de situações problemáticas que sejam mais

3 Transcrição do texto à esquerda: Movimento uniforme é quando duas engrenagens estão grudadas se você roda uma, todas ficam rodando, quantas engrenagens que você quiser.

Transcrição do texto à direita: Para usar menos força você precisa não levantar muito porque você vai usar mais força. Mas se levantar você vai aumentar a distância e você vai usar mais força. 
valorizadas em relação a um ensino exclusivamente compartimentado e instrucional baseado numa relação unilateral entre professor e aluno.

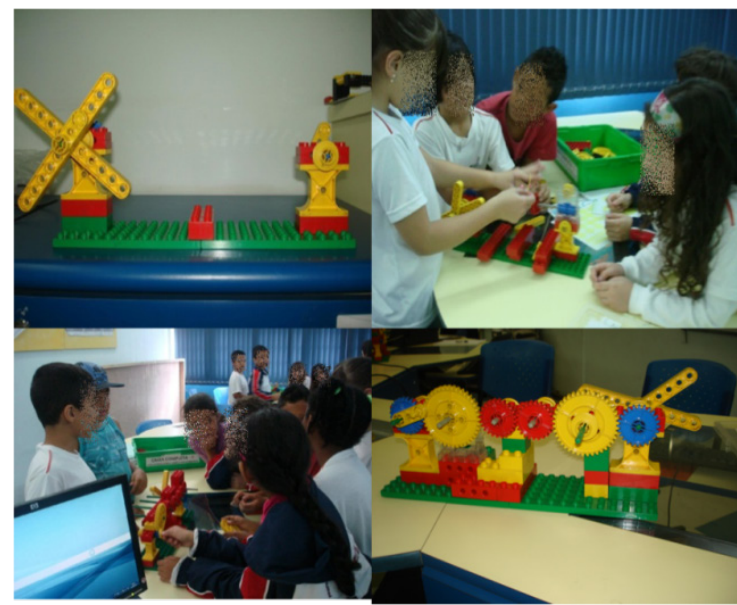

Figura 9. Montagem padrão, grupos dialogando para solucionar o problema e o primeiro grupo que conseguiu concluir a atividade explicando aos demais

O episódio 2, registrado por filmagem, apresenta a fala de uma aluna que, ao deparar-se com uma informação de um site, julga-a duvidosa e a questiona coletivamente. A aluna S, se posicionando sobre a informação de um dos sites utilizados durante a pesquisa que afirmava "não haver um inventor para o carro", argumenta perante o grupo:

\section{Episódio 2:}

Ninguém inventou o carro? Como que o carro foi inventado? O carro não inventou a ele mesmo, né! - aluna S.

Obviamente que a intenção do site era não atribuir a um único nome a responsabilidade pela invenção do carro, mas apresentá-lo como uma elaboração processual histórica. Porém, ao não mencionar ao menos alguns personagens envolvidos e suas contribuições, fez com que o texto deixasse a invenção do carro como uma "aparição espontânea", o que chamou a atenção da aluna pelo fato de já ter sido conversado em aula que todo aparato tecnológico é uma construção humana e que sofre modificações ao longo do tempo.

No episódio 3, relatado a partir de anotações no diário de observação, durante a etapa da pesquisa na internet a turma A atuou de modo surpreendente. Ao serem avisados pela PAPE que as afirmações sobre a história da catapulta poderiam não ser precisas e, tendo a necessidade de informações precisas para o próximo passo do trabalho, os alunos são instigados a encontrarem uma alternativa.

\section{Episódio 3:}

Isso é fácil de resolver, a gente pesquisa de novo - aluno L.

É prô, tem que olhar em muitos sites da Internet, lembra? - aluna M. 
Aí a gente podia arrumar a Internet para nenhuma pessoa do mundo ficar sendo enganada - aluno R.

Ah é? E como podemos arrumar a Internet? Será que conseguimos mexer no que as pessoas criaram? - pesquisadora.

Então a gente cria um site contando para todo mundo que tem sites que falam mentiras e até fala que tem os que falam a verdade. Todo mundo vai gostar - aluna C.

Os episódios 2 e 3 remetem a situações nas quais os alunos apresentam uma postura crítica diante de informações veiculadas na internet. Avaliar uma informação e se posicionar sobre a mesma é um indício da formação de uma postura crítica, ainda mais na faixa etária em que estas crianças se encontram. Promover situações nas quais o aluno tenha condições de avaliar, emitir opiniões, reconsiderar e comprovar é, acima de tudo, dar condições para o desenvolvimento de posturas investigativas e argumentativas (Santos, \& Galembeck, 2018) que levam à criticidade, elemento constituinte de um processo de educação científica. Pelo episódio 3, é possível perceber o quanto este grupo se sentia responsável e capaz de contribuir com uma rede de publicação e divulgação de conteúdos, evidenciando que a criticidade e atitudes científicas estavam se constituindo na turma.

\section{Atribuição de sentidos e relações com o cotidiano}

Considera-se que o aprendizado se torna significativo quando ultrapassa as fronteiras da escola e começa a fazer sentido no estabelecimento de relações com o cotidiano de forma espontânea. Durante uma reunião de pais e mestres na qual o projeto foi apresentado, alguns pais fizeram colocações que nos remeteram a implicações do trabalho realizado. O episódio 4, registrado no diário da pesquisadora, expressa o relato de uma mãe durante a reunião.

\section{Episódio 4:}

Eu imaginei que tinha alguma coisa diferente, pois quando passamos em frente ao Tomé ${ }^{4}$ o A me deu uma aula sobre polias, roldanas e o peso que os guindastes conseguem erguer por conta disso tudo. Ele falou que até as pessoas erguem mais peso quando usam mais polias, porque a força aumenta - mãe do aluno A.

Ainda sobre a atribuição de sentidos aos conteúdos abordados e a suas relações com o cotidiano, em uma visita a um museu de ciências chamado Catavento, no final do mês de outubro, a professora da turma A solicitou o acompanhamento da pesquisadora ao ser informada que o roteiro destinado à sua turma era composto pelas seções "vida - engenho - nanotecnologia”. Ambas acharam por bem aproveitar a visita ao setor "engenho" para observar possíveis relações entre os conteúdos trabalhados no projeto e os abordados pelos monitores do museu. O diálogo no episódio 5, registrado no diário de observação da pesquisadora, exemplifica tais relações quando a turma chegou a um

4 Tomé: empresa especializada em aluguéis de guindastes e gruas de grande porte, entre outros. 
dispositivo que consistia numa bicicleta que, quando pedalada, acendia um conjunto de lâmpadas.

\section{Episódio 5:}

Quem é forte para pedalar esta bicicleta bem rápido? - monitora.

Diversas manifestações de indicação própria do grupo.

Mas precisa ser tão forte que aquelas lâmpadas precisam acender. Vamos medir quem vai acender uma ou todas. Façam uma fila de quem quer tentar - monitora.

Depois de algumas tentativas dos estudantes, umas com êxito pleno outras não, a monitora pergunta:

Muito bem, mas estou com um problema. Como será que estas lâmpadas acendem quando a gente pedala com força? Será que tem um interruptor lá dentro? Será que conseguimos fazer energia? - monitora.

Claro que sim! O nosso corpo faz a energia mecânica que era só o que existia quando não tinha energia da tomada - aluna MF.

Após outras manifestações dos alunos sobre o conceito de energia, falando de suas experiências sobre a conversão da energia mecânica em eletricidade, a monitora procura com os olhos a professora que está com um grupo em outro equipamento e, percebendo a presença da pesquisadora, sorri.

É isso mesmo! Mas como vocês sabem disso?- monitora.

A prô Verônica ensinou e eu sei que aí dentro tem um monte de engrenagens que faz a gente pedalar aqui e acender lá - aluno R.

Igual o joguinho de colocar as engrenagens para a luz chegar nas casas - aluno P.

Em sua fala, o aluno P refere-se a um jogo virtual ilustrativo utilizado para demonstrar outras aplicações da integração de engrenagens de tamanhos diferentes vistas em aula, como na transmissão da energia elétrica.

Depois de uma explicação rápida sobre o projeto e os principais conteúdos para a monitora, que se interessou em compreender como crianças de seis e sete anos tinham noções muitas vezes ausentes em alunos de séries mais avançadas que visitam o setor, a mesma parabeniza o grupo e os incentiva a continuarem estudando. Relatos como estes indicam que os conteúdos abordados no projeto se tornaram vivos, prazerosos e significativos. Quando as crianças associam conteúdos escolares a situações do cotidiano, atribuindo sentidos e contextualizando-os, pode-se concluir que os mesmos passaram a ter um significado diferenciado para elas, com função social e contribuindo para sua formação científica.

\section{A autoria e o protagonismo infantil}

Visando oferecer oportunidades para o desenvolvimento do protagonismo infantil, da autoria e que os alunos pudessem sistematizar alguns conhecimentos construídos, 
foi planejada desde o início do projeto a elaboração de um álbum de figurinhas, que se caracteriza por ser uma produção concreta, com função social real e de interesse para a faixa etária da turma. O álbum contém informações referentes aos contos, às invenções tecnológicas, aos mecanismos e aos conceitos abordados nos eixos. A redação dos textos para o álbum se deu de modo individual, no que se refere à responsabilidade de cada criança em construir sua parte, porém surpreendentemente colaborativa em relação à liberdade de expressão, cooperação e sentimento de construção coletiva que predominou na sala durante esta atividade.

Cada etapa para a construção do álbum - produção escrita, digitação e seleção das imagens para as folhas de figurinhas - foi de responsabilidade dos alunos, estando representadas na Figura 10. A atuação da professora se deu no auxílio à produção escrita para os alunos que se encontravam ainda em fase de alfabetização, como uma ação de intervenção a bem do avanço no processo de escrita e, posteriormente, na revisão textual realizada durante a fase de digitação. Por sua vez, a pesquisadora atuou na edição e impressão do álbum, por serem estas atribuições da PAPE no exercício de suas funções.

A postura ativa dos alunos perante os conteúdos e estratégias, verificada na elaboração do álbum, indicam possibilidades para o desenvolvimento de um currículo organizado em torno da investigação, da flexibilidade, da liberdade, da colaboração e da autoria do aluno, mediadas com o uso contextualizado das TIC (Almeida, 2008). A Figura 11 traz imagens ilustrando partes do álbum construído pelas crianças.

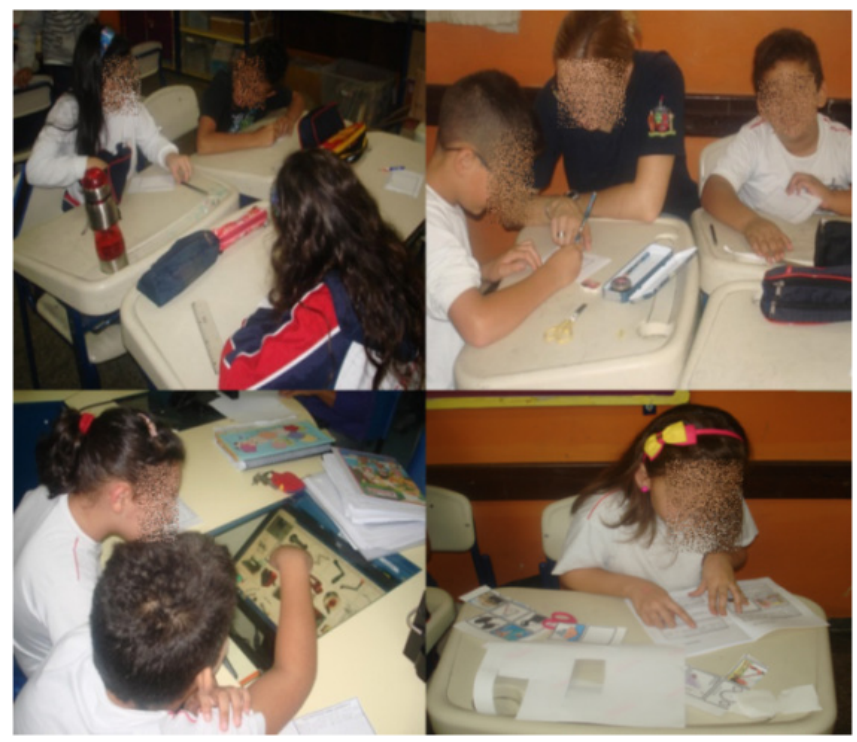

Figura 10. Sequência de imagens ilustrando o processo de construção do álbum de figurinhas 

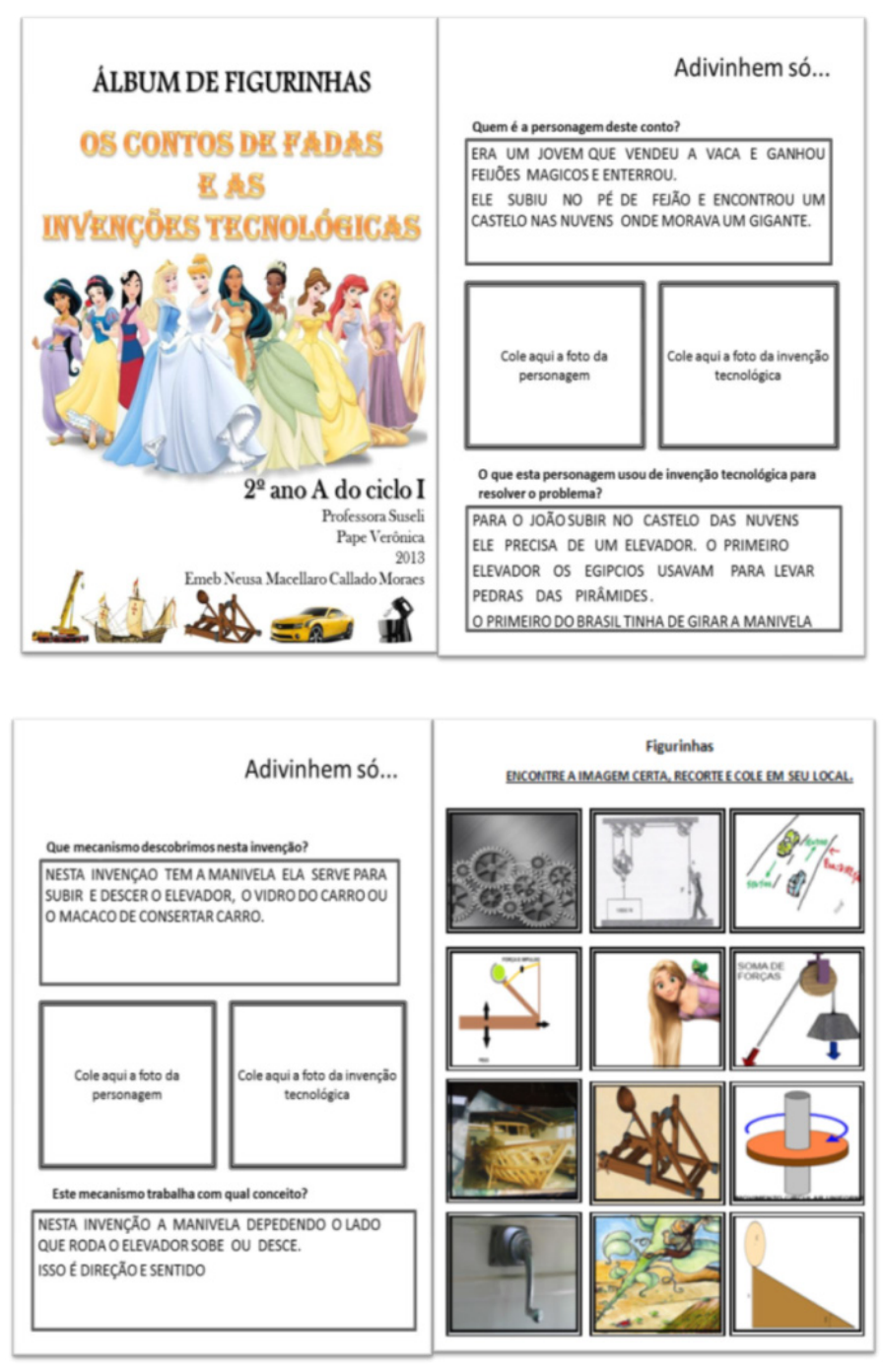

Figura 11. Reprodução da capa do álbum de figurinhas, das páginas internas referentes ao eixo 1 e de uma das folhas de figurinhas para colagem

\section{Considerações finais}

Finalizamos o presente artigo apresentando nossas considerações no sentido de retomar os objetivos da investigação, refletindo sobre suas contribuições e limitações para a educação científica mediada por recursos tecnológicos nos anos iniciais do ensino fundamental.

Em alguns momentos no desenvolvimento das atividades deparamo-nos com limitações de ordem técnica, relacionadas à qualidade do sinal da internet na escola e a equipamentos que apresentaram defeitos. Mesmo em uma escola com boa infraestrutura em sua sala de informática, como a que integrou o presente projeto, problemas dessa natureza acontecem. O trabalho com as TIC demanda que as instituições escolares estejam preparadas para oferecer as condições técnicas necessárias. A figura da PAPE 
se revelou fundamental para auxiliar as professoras diante desses problemas técnicos, orientando-as com relação ao funcionamento dos equipamentos e motivando-as a continuar os trabalhos mesmo quando as dificuldades surgiam. Fica evidenciado que em escolas sem tal apoio aos professores, a probabilidade de se desenvolverem projetos efetivos de inserção pedagógica das TIC é reduzida, ainda que os professores demonstrem interesse em realizá-los. Nesse sentido, políticas públicas poderiam contribuir através da garantia da oferta de sinal de internet de qualidade para as escolas, de equipamentos de informática e suporte técnico para sua manutenção e atualização.

No que se refere aos aspectos pedagógicos, a formação dos professores para o trabalho em uma perspectiva construtivista em sua vertente sociocultural, que centraliza a posição do aluno nos processos de ensino e aprendizagem com o uso de metodologias ativas, se faz necessária de modo contínuo. $\mathrm{O}$ uso das TIC e de quaisquer outros recursos que potencializariam inovações devem ser pautados em uma definida intencionalidade pedagógica. Do contrário, não há transformação no ambiente da sala de aula e a tendência é que se reproduzam práticas instrucionais pouco eficientes e atrativas para o aluno. $\mathrm{O}$ apoio pedagógico às professoras se deu em nosso projeto pela interação entre elas e os pesquisadores, através de uma parceria colaborativa aproximando escola e academia de modo equânime, não hierárquico. $\mathrm{O}$ projeto foi delineado em conjunto a partir das demandas, das necessidades apontadas pelas professoras e do currículo da escola. Esse é o caminho que indicamos para a efetivação de novos projetos nas diferentes realidades escolares.

O desenvolvimento de uma postura científica por parte das crianças é evidenciado pelos seus atos de questionamento e argumentação, busca orientada por informações com seleção e classificação das mesmas, tentativas de sistematização e aplicação conceitual, tal como na mobilização de conhecimentos constituídos em um contexto escolar para explicar outras situações, conforme verificado nos episódios 4 e 5 . Trata-se da constituição de habilidades pertinentes ao fazer científico com a realização de operações epistêmicas como levantamento e seleção de informações, classificações, análises e aplicações conceituais em situações cotidianas da criança.

No que se refere à área de pesquisa em ensino de ciências, há uma carência de investigações de caráter prático sobre as relações entre tecnologias e práticas de ensino de ciências nos anos iniciais do ensino fundamental. Nossa investigação contribui para essa temática, fornecendo subsídios para novas pesquisas que compartilhem dos referenciais que adotamos. Desenvolvemos um projeto que integrou o uso das TIC no decorrer de todo ano letivo, não se limitando à realização de atividades pontuais com os recursos tecnológicos. Contribuímos com uma proposta de ação educacional que aproxima as recomendações teóricas da sala de aula, com o intuito de contribuir para o estabelecimento de novas relações de ensino e aprendizagem, uma mudança gradativa na realidade escolar conforme os princípios da pesquisa ação. Além disso, a disponibilização dos produtos das atividades realizadas no site permite que outros educadores possam analisar e reaplicar a proposta, adaptando-a a seus contextos e atentando-se aos detalhes 
explicitados no repositório virtual, para também elaborarem seus próprios projetos.

Tecnologias integradas de forma contextualizada e significativa ao currículo, com uma proposta pedagógica baseada na construção do conhecimento por meio de atividades investigativas, tem um potencial que consideramos ter sido explorado através das dimensões analisadas na presente pesquisa. É possível afirmar que parte considerável dos sentidos atribuídos pelos estudantes dificilmente seria alcançada sem a utilização das tecnologias como mediadoras do processo educacional e a diversificação de estratégias. Propiciar aos alunos uma participação ativa e efetiva exige da escola versatilidade a fim de que possa caminhar articulada com a sociedade, tornando o conhecimento científico mais acessível a todos e democratizando o acesso à informação e à comunicação (Pretto, \& Pinto, 2006). A utilização das tecnologias para a produção virtual ou real torna a autoria um objetivo acessível, permitindo também a abordagem de aspectos éticos, morais e legais relacionados às TIC. $\mathrm{O}$ acesso às informações e à produção científica, assim como a possibilidade dos alunos se posicionarem criticamente e socialmente, é uma potencialidade das TIC que foi explorada no projeto. $\mathrm{O}$ uso didaticamente intencional dos recursos tecnológicos consiste em um modo de, no âmbito da escola, promover o incremento na autoestima das crianças pela sua inserção em questões próprias de seu tempo.

Os episódios apresentados, que evidenciam situações de argumentação, reflexão crítica e desenvoltura investigativa, mostram que é possível utilizar as tecnologias de forma a contribuir para formação integral do sujeito, na constituição de um perfil atuante e atitudes pertinentes ao fazer científico desde os anos iniciais da educação escolar. As relações estabelecidas entre termos e conceitos científicos com o cotidiano se tornaram possíveis com a utilização de recursos e estratégias que, com a mediação das professoras e da PAPE, propiciou aos alunos estabelecerem associações entre tais conceitos abstratos e situações vivenciadas além do ambiente escolar. A identificação, retomada e associação dos conteúdos de forma contextualizada, evidenciada em posicionamentos diversos, demonstram a atribuição de sentidos e a funcionalidade social do conhecimento científico para os alunos.

Um aspecto essencial para a efetividade do ensino de ciências através da utilização das TIC com vistas à formação para a cidadania, tão almejada atualmente, é a concepção educacional do professor e suas bases epistemológicas. Diante de uma postura passiva, de uma visão tradicional de ensino que é entregue compartimentado e não discutido com os alunos, não há recursos e caminhos que conduzam a uma formação integral, construtiva, argumentativa e crítico-investigativa. Só haverá sempre a reprodução imutável e acrítica do que já existe. Somente mais do mesmo. Por fim, para ilustrar o que esta pesquisa buscou apresentar como primordial no processo educativo e que justifica lançar mão de recursos, instrumentos e estratégias para diversificar as práticas colocando o aluno como centro e protagonista da sua aprendizagem, nós resgatamos do encontro de Paulo Freire com Seymour Papert ${ }^{5}$ um trecho crítico acerca de uma

5 O encontro entre Paulo Freire e Seymour Papert ocorreu no início dos anos de 1990, na Universidade de São Paulo. Um trecho pode ser apreciado em: http://www.youtube.com/watch?v=BejbAwuEBGs 
concepção educacional baseada na ideia de transmissão de conhecimentos.

Em uma piada clássica, uma criança fica depois da aula para fazer a pergunta: "Professora, o que eu aprendi hoje?”.
A professora, com ar de surpresa, questiona:
"Por que está perguntando isso?”. A criança responde:
“Papai sempre me pergunta e eu nunca sei o que dizer!”.
Seymour Papert

\section{Referências}

Alisson, E., \& Goldston, M. J. (2018). Modern Scientific Literacy: A Case Study of Multiliteracies and Scientific Practices in a Fifth Grade Classroom. Journal of Science Education and Technology, 27, 270-283.

Almeida, M. E. B. (2008). Tecnologias na educação: dos caminhos trilhados aos atuais desafios. Bolema, 21(29), 99-129.

Ariza, M. R., \& Armenteros, A. Q. (2014). Nuevas tecnologías y aprendizaje significativo de las ciências. Ensenanza de las ciências, 32(1), 101-115.

Bardin, L. (2011). Análise de conteúdo. São Paulo: Editora 70.

Bingimlas, K. A. (2009). Barriers to the successful integration of ICT in the teaching and learning environments: a review of the literature. Eurasia Journal of Mathematical, Science \& Technology Education, 5(3), 235-245.

Blalock, C. L. Lichtenstein, M. J., Owen, S., Pruski, L., Marshall, C., \& Toepperwein, M. (2008). In pursuit of validity: a comprehensive review of science attitude instruments 1935-2005. International Journal of Science Education, 30, 961-977.

Bogdan, R. C., \& Biklen, S. K. (1994). Investigação Qualitativa em Educação. Porto: Porto Editora.

Buckingham, D. (2010). Cultura digital, educação midiática e o lugar da escolarização. Educação e Realidade, 35(3), 37-58.

Costa, F. A., Rodriguez, C., Cruz, E., \& Fradão, S. (2012). Repensar as TIC na educação: o professor como agente transformador. Lisboa: Santillana.

Cuban, L. (2001). Oversold and underused: computers in the classroom. Cambridge, MA: Harvard University Press. 
Kerr, K., \& Murphy, C. (2012). Children's attitudes to primary science. In Fraser, B., Tobin, K., \& McRobbie, C. (eds.) Springer International Handbook of Education, 1, 627649. Dordrecht, The Netherlands: Springer.

McNaughton, S., Rosedale, N., Jesson, R., Hoda, R., \& Teng, L. (2018). How digital environments in schools might be used to boost social skills: Developing a conditional augmentation hypothesis. Computers \& Education, 126, 311-323.

Murphy, C. (2012). Vygotsky and primary science. In Fraser, B., Tobin, K., \& McRobbie, C. (eds.) Springer International Handbook of Education, 1, 627-649. Dordrecht, The Netherlands: Springer.

Murphy, C., \& Beggs, J. (2003). Children's perceptions of school science. School Science Review, 84 (308), 109-116.

Nunes, T. S., \& Motokane, M. T.(2015). Características das hipóteses em sequências didáticas investigativas. Anais X Encontro Nacional de Pesquisa em Educação em Ciências - Águas de Lindóia, SP, p.1-8.

Ogborn, J. (1997). Constructivist metaphors of learning science. Science \& Education, $6,121-133$.

Osborne, J. \& Hennessy, S. (2003). Literature review in science education and the role of ICT: promise, problems and future directions. London: Futurelab Research. Report 6.

Oliveira, M. K de. (2006). Vygotsky. Aprendizado e desenvolvimento: um processo sóciohistórico. $4^{\text {a }}$ ed. São Paulo: Scipione.

Pretto, N., \& Pinto, C. C. (2006). Tecnologias e novas educações. Revista Brasileira de Educação, 11 (31), 19-30, 2006.

Santos, V. G., Almeida, S. E., \& Zanotello, M. (2018). A sala de aula como um ambiente equipado tecnologicamente: reflexões sobre formação docente, ensino e aprendizagem nas séries iniciais da educação básica. Revista Brasileira de Estudos Pedagógicos, 99(252), 331-349.

Santos, V., \& Galembeck, E. (2018). Sequência Didática com Enfoque Investigativo: Alterações Significativas na Elaboração de Hipóteses e Estruturação de Perguntas Realizadas por Alunos do Ensino Fundamental I. Revista Brasileira De Pesquisa Em Educação Em Ciências, 18(3), 879-904. https://doi.org/10.28976/19842686rbpec2018183879

Sasseron, L. H. (2015). Alfabetização científica, ensino por investigação e argumentação: relações entre ciências da natureza e escola. Ensaio Pesquisa em Educação em Ciências, 17(especial), 49-67.

Silva, C. de S., \& Penido M. C. M. (2011). Uma leitura sobre problematizações no ensino de ciências. Anais VIII Encontro Nacional de Pesquisa em Educação em Ciências, Campinas, SP. 
Souza, M. A., \& Fazenda, I. C. A. (2017). Interdisciplinaridade, currículo e tecnologia: um estudo sobre práticas pedagógicas no ensino fundamental. RIAEE - Revista IberoAmericana de Estudos em Educação, 12(2) 708-721.

Thiollent, M. (2011). Metodologia da pesquisa-ação. $18^{\mathrm{a}}$ ed. São Paulo: Cortez.

Valente, J. A. (1999). O computador na sociedade do conhecimento. Campinas-SP: UNICAMP/NIED.

Webb, M. E. (2005). Affordances of ICT in science learning: implications for an integrated pedagogy. International Journal of Science Education, 27(6) 705-735.

Zandvliet, D. B. (2012). ICT learning environments and science education: perception to practice. In Fraser, B., Tobin, K., \& McRobbie, C. (eds.) Springer International Handbook of Education, 1, 627-649. Dordrecht, The Netherlands: Springer.

Zanotello, M., Studart, N., Torel, A. C. C., Esturari, E. B. M., Zocoler, F. A. S., \& Santos, V. G. (2017). TIC e ensino de ciências na educação básica: a construção de um site sobre o sistema reprodutor humano. Enseñanza de las Ciencias, n. extra, 1135-1140.

Verônica Gomes dos Santos

${ }^{\oplus}$ https://orcid.org/0000-0003-2270-014X

Unicamp

Programa de Pós-Graduação Multiunidades em Ensino de Ciências e Matemática São Bernardo do Campo, São Paulo, Brasil veronicagsantos@yahoo.com.br

Marcelo Zanotello

${ }^{-1}$ http://orcid.org/0000-0003-2661-8637

UFABC

Santo André, São Paulo, Brasil marcelo.zanotello@ufabc.edu.br

Submetido em 03 de maio de 2019

Aceito em 01 de novembro de 2019

Publicado em 03 de dezembro de 2019 